\title{
Morphofunctional changes in the digestive organs of pigs under the influence of soy processing product-okara
}

\author{
Svetlana Karamushkina ${ }^{1,{ }^{*}, \text { Elena } \text { Kuryatova }^{1} \text {, Olesay Gruzdova }}{ }^{1}$, and Alena Kornilova $^{1}$ \\ ${ }^{1}$ Far Eastern state agricultural University, Blagoveshchensk, Russia
}

\begin{abstract}
Okara obtained by processing soy grown in the Amur region contains twice as much raw and digestible protein as the product produced in the Western regions of our country. According to zootechnical analysis, it contains a mass fraction of crude protein of $29.58 \%$ and the amount of digested protein of $266.22 \mathrm{~g}$. Its unnormalized use as a protein Supplement during intensive fattening of pigs causes fatty dystrophy of acinar cells and infiltrative growth of adipose and connective tissue, degenerative degeneration of the endocrine part of the glandular epithelium of the pancreas. Observed in liver cirrhotic transformation and protein-fatty degeneration of hepatocytes In 12-duodenum of piglets us were diagnosed with moderate diffuse chronic atrophic duodenitis, which manifests as thinning of the mucosa, flattening of surface epithelium, reducing the number of crypts and villi. The results of histological studies of the main digestive glands (pancreas and liver), as well as the small intestine allow us to conclude that soy Okara from Amur producers has a negative effect on the morpho-functional state of the digestive system, and as a result, a decrease in the digestibility and digestibility of nutritional components of the feed.
\end{abstract}

\section{Introduction}

In the pig industry, there is a constant problem of lack of protein and amino acids in the diet of fattening young animals. Feeders often use soy and its processed products such as soy meal, cake, and flour to balance their protein diets. [1]

As an additional source of protein, many farms in the Amur region that specialize in fattening pigs and cattle use the product of soy processing - Okara.

Okara is a soy mass that is formed when soy milk is obtained from soy beans. Okara almost does not contain fat, but it contains a lot of fiber (12-14. $5 \%$ in dried Okara), protein ( $24 \%$ in dried Okara), calcium, iron, Riboflavin. Okara is the only plant source of bivalent iron, which is easily digested by the body.

Summarizing the results of research by domestic and foreign authors on the chemical composition of soy Okara dry matter, it can be presented as follows: the protein content ranges from 5.3 to $32.2 \%$, fat — from 3 to 22.2 , dietary fiber - from 6.75 to $58.1 \%$.

\footnotetext{
*Corresponding author: sveta.vetmed@mail.ru
} 
According to the authors, the component composition of soy Okara is unstable and depends on the degree of dehydration and processing technology of beans [1,2].

Unlike other soy products, Okara does not contain anti-nutritional substances such as protease inhibitors and urease. However, when soy Okarawas added to the main diet as a protein Supplement, there was no predicted increase in average daily weight gain in fattening young animals. [4]

After conducting a complete zootechnical analysis of soy Okara from Amur producers, a relatively high content of the mass fraction of raw protein $29.58 \%$ and the amount of digested protein $266.22 \mathrm{~g}$ was identified.

Table 1. Complete zootechnical analysis of soy processing waste " Okara» (according to the conclusion of the Federal state budgetary institution "station of agrochemical service "Amurskaya»).

\begin{tabular}{|c|c|c|c|}
\hline № & Analyzedindicator & Unitofmeasurement & Measuringresult \\
\hline 1. & Massfractionofnitrates & Mln $^{-1}$ & $199 \pm 28$ \\
\hline 2 & Mass fraction of dry matter determination & $\%$ & $17.01 \pm 1,42$ \\
\hline 3 & Mass fraction of crude protein & $\%$ & 29.58 \\
\hline 4 & Mass fraction of raw fat & $\%$ & $13.77 \pm 1 / 06$ \\
\hline 5 & Mass fraction of crude fiber & $\%$ & $16.16 \pm 1 / 73$ \\
\hline 6 & The content of crude ash & $\%$ & 4.61 \\
\hline 7 & Massfractionofcalcium & $\%$ & $0.35 \pm 0.06$ \\
\hline 8 & Massfractionofphosphorus & $\%$ & $0.47 \pm 0.08$ \\
\hline 9 & Feedunit & $\mathrm{kg}$ & 1.43 \\
\hline 10 & Exchangeenergy & $\mathrm{MJ} / \mathrm{kg}$ & 13.3 \\
\hline 11 & Digestibleprotein & $\mathrm{g}$ & 266.22 \\
\hline 12 & Mass fraction of soluble carbohydrates & $\%$ & $7.52 \pm 1.04$ \\
\hline
\end{tabular}

A large amount of protein and free amino acids contained in soy Okara can have a negative impact on the functional and morphological state of the digestive organs of farm animals and thereby reduce their productive qualities, especially when used abnormally. [5]

The purpose of our work is to study the morphological changes in some digestive organs of young pigs and cattle when using soy Okara as a protein Supplement.

\section{Method of research}

The research was conducted on the basis of A.V. Ponomarev's peasant farm, which specializes in fattening pigs. the Farm is located in the Blagoveshchensk district of the Amur region. To conduct research using the method of paranalogs, a group of animals was formed from 5 heads. Piglets at the age of 4 months were selected for experimental groups. Animals for 3 months received as a protein Supplement the product of soy processingOkara, produced at the Blagoveshchensk dairy plant from local varieties of soy.

After the planned slaughter of pigs, samples of the pancreas, liver and small intestine were selected for histological examination and assessment of their morphofunctional state, which was recorded in $10 \%$ water neutral formalin and Carnoisic liquid, dehydrogenated in alcohols of increasing strength, poured into paraffin blocks, made histosections on a sledge microtome MS-2, 4-6 microns thick and stained with hematoxylin and eosin, as well as by van gieson common methods. Photos were taken using the Altami 104 microscope and Samsung ST 50 digital photography.

\section{Results}

The study of histological preparations from the pancreas of experimental animals revealed changes characteristic of chronic pancreatitis and lipomatosis. In this case, macroscopically, 
the color of the organ is gray-white, there is an increase in the size of the gland, the structure is lobular. Its parenchyma is edematous, its tissue is dense, more or less replaced by adipose tissue, protrudes above the surface of the incision, with pronounced fibrosis, especially in the area of the head (Fig. 1).

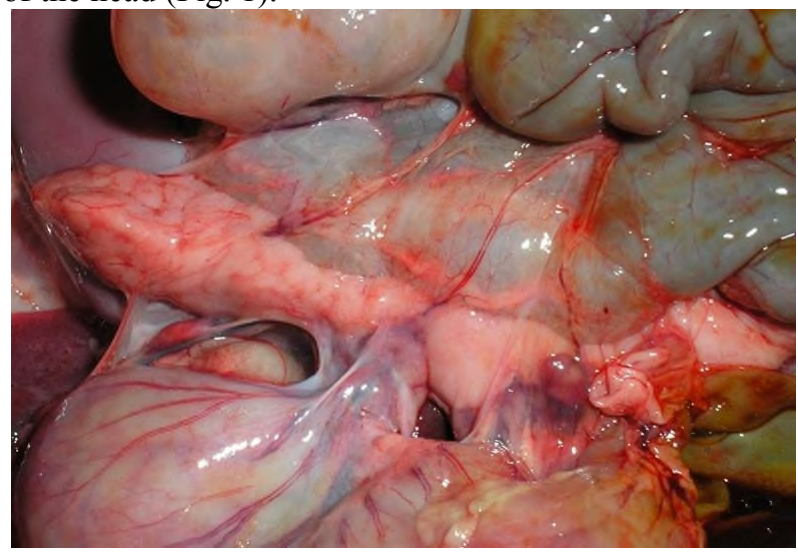

Fig. 1. Pancreas of piglets that received soy Okara as a protein Supplement: 1-lobular structure and edema of the pancreas.

When histological examination is clearly visible pronounced discomplexation of enzocrineacinuses, that is, there is a violation of the ratio of cellular elements and tissue (Fig. 2). Ekzokrinnye trapezoidal shape, with round nuclei. In the tissue of some cells, there were violations of secretory activity, which was manifested by the accumulation of granulelike structures in the apical part of granulocytes. In places, the zoning of the cytoplasm is erased, the cytoplasm is foamy, and the boundaries of acinar cells are not clear. Connective tissue strands in some areas penetrate and branch in the depth of the lobes which indicates the development of fibrosis in the pancreas. In places, acinar cells are replaced by vacuoles of various sizes (from small to large, sometimes merging with each other) optically empty (intra-lobular lipomatosis). Medium-sized insular Islands of Langerhans without any signs of hyperplasia are intact. [6]

In this case, piglets that received soy Okara as a protein Supplement were found to have lipomatosis and pancreatic fibrosis, which manifested as fatty dystrophy of acinar cells with the accumulation of a large number of lipid drops in their cytoplasm and infiltrative growth of fat and connective tissue with gradual replacement of its exocrine part.

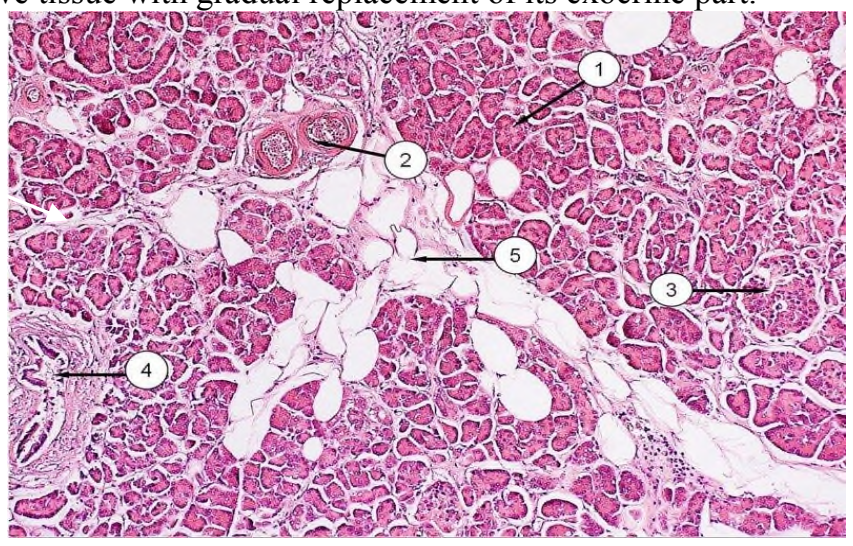

Fig. 2. Pancreas of pigs that received soy Okara as a protein Supplement. Color with hematoxylin and eosin; UV. 150. 1 - exocrinocytes of trapezoid shape; 2-blood vessels; 3-intact islet of Langerhans; 4excretory duct; 5 - site of pancreatic lipomatosis. 
The liver, in experimental animals, is enlarged in volume, the surface is unevenly colored, on a light cherry background there are areas of dark red and grayish-reddish color, flabby consistency, the capsule is tense, the edges are rounded (Fig. 3).

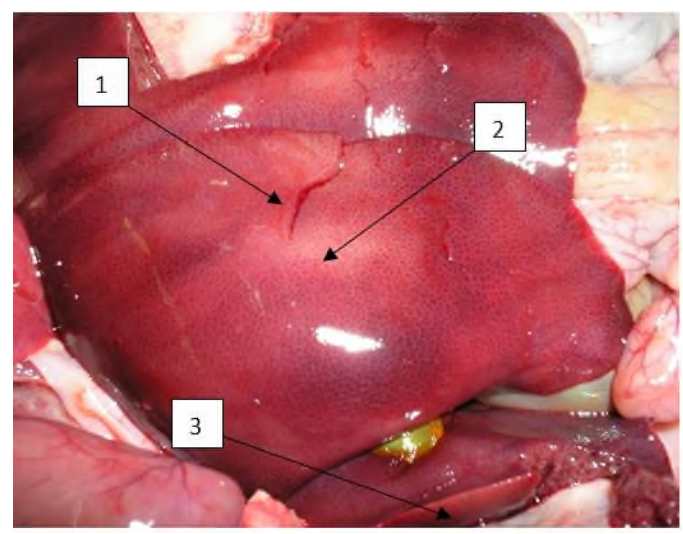

Fig. 3. Liver of piglets that received soy Okara as a protein Supplement: 1-liver rupture; 2-pale areas; 3 - thickening of the edge of the organ.

The incision surface is uneven with areas of deposits and mosaic color, a large amount of blood flows from the incision surface, the pattern of the liver lobes is clearly expressed; the gall bladder contains a small amount of greenish bile (about $10 \mathrm{ml}$ ), the mucous membrane is yellowish-greenish, velvety, the wall thickness is about $1 \mathrm{~mm}$.

Histological studies of liver preparations revealed that the layers of connective tissue at the border of the liver lobes are sharply expressed with the formation of small nodesregenerates, fibrous septa are colored red by van gieson (Fig. 4A). The Central veins of the lobes are dilated, full-blooded. The sinusoids of the Central divisions of the lobes are sharply expanded and full-blooded. In hepatocytes, there was a decrease in the size of the nuclei and the Erasure of the pattern (karyopiknoz), and an increase in their size, and a lighter color (karyolysis). Hepatocytes are atrophic, with focal vacuole round-drop dystrophy. Hepatic beams disconnexion, thinned. [7, 8]

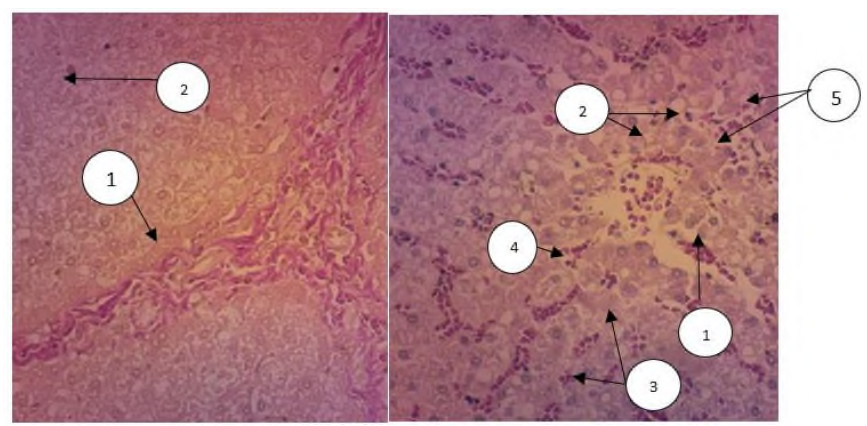

A

$\mathrm{B}$

Fig. 4. Liver of pigs that received soy Okara as a protein Supplement. A) 1 - fibrous septa; 2 decompensate hepatic structural beams, stained by van gieson; SW. 150 B) - 1 - Central vein lobules enlarged and plethoric; 2 - globular fatty degeneration; 3 - sinusoids dilated and full-blooded; 4 karyolysis in hepatocytes; 5 - large, medium and atomized fatty degeneration; hematoxylin and eosin; HC.150. 
The cells of the peripheral parts of the liver lobes have a granular cytoplasm, and their nuclei are light. Among the hepatocytes subjected to granular dystrophy, there were liver cells in a state of necrosis and necrobiosis. Kupfer cells in the stage of proliferation, increased in volume, sometimes formed clusters. There was also a decrease in the number of unchanged and dual-core cells, an increase in holonuclear cells, and the appearance of non-nuclear liver cells. The regenerative capacity of the liver was sharply reduced, which was manifested by the absence of dual-core liver cells. The phenomena of degeneration of liver cells tended to progress, and the liver lobules lost their trabecular structure.

This pattern is typical for chronic venous fullness of the liver with cirrhotic transformation, protein-fat dystrophy of hepatocytes. [9]

In the small intestine, the mucosa is swollen, grayish-matte or grayish-red, with focal hyperemia mainly at the height of the folds. The folds are thickened. The intestines are swollen (Fig. 5). In most piglets, the mucous membrane of the small intestine is covered with a semi-thick or viscous mucous content.

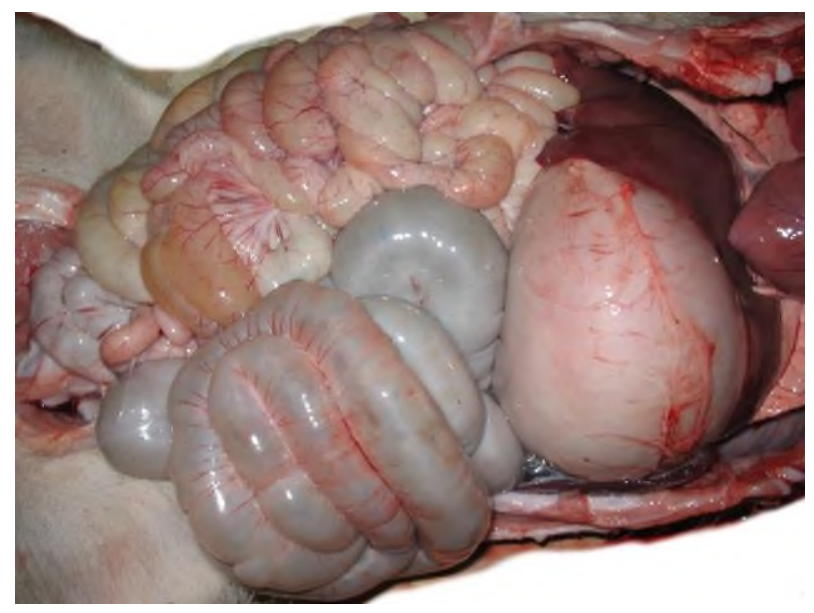

Fig. 5. Intestinal Flatulence in piglets that received soy Okara as a protein Supplement.

Histological studies revealed that in the area of pits and rollers, the infiltrate of the proper plate of the 12-duodenal mucosa and epithelium was represented by polymorphonuclear leukocytes, as well as an increase in the number of neutrophils with moderate leukopedesis, which indicated a moderate inflammatory process. In the submucosal base of the duodenum, Brunner's glands with the usual structure (Fig. 6A). The villi are deformed and shortened. There was a moderate hypertrophy of superficial edged epithelial cells, which were in a state of granular dystrophy. Hyperchromic nuclei of these cells were located basally in the cytoplasm. The height of columnar epithelial cells of the villi decreased, but, nevertheless, they had a cylindrical shape (Fig. 6A). Their hyperchromic nuclei shifted in the cytoplasm to a third of the height of the cell. Eosinophilic cytoplasm of villi epithelial cells was in a state of granular and vacuole dystrophy. The thickness of the striated border of epithelial cells of the villi did not change, but it became sparse and lost its clear contours.

Deep duodenal glands completely preserve the epithelial lining, and secretions were found in their cavities. Proliferates were detected around glandular structures, which are represented by macrophages, plasmocytes, and lymphocytes. In the muscle envelope, the annular and longitudinal muscle fibers do not have clear boundaries and irregularly colored elongated myocyte nuclei are arranged in a chain. The serous membrane is thickened and covered with elongated mesothelial cells, some of which are rejected. 
The surface epithelium is flattened and desquamated. In its own plate of the mucous membrane and the subject of loose fibrous connective tissue - lymphoplasmocytic and eosinophilic infiltration, edema. There was a deepening and decrease in the number of crypts, an expansion of their lumen, a decrease in the number of goblet cells and Panet cells (Fig. 6 B). In some cases, focal necrosis of villi and glands was observed near the own plate of the mucous membrane, and in the preserved glandular structures, desquamation of epithelial cells with a goblet shape was noted.

Moderate diffuse atrophic chronic duodenitis was diagnosed in the 12-duodenum of piglets that received soy Okara as a protein Supplement.

Chronic atrophic diffuse duodenitis is characterized by thinning of the mucous membrane, flattening of the surface epithelium, a decrease in the number of crypts, villi, epithelium, including goblet cells, and hyperplasia of smooth muscle elements. At the same time, connective tissue grows, both in its own layer and in the submucosal base. The stroma is heavily infiltrated by neutrophils, eosinophils, lymphocytes, and plasma cells. The diffuse nature of inflammation is confirmed by the defeat of the entire thickness of the mucous membrane, accompanied by dystrophic changes in the surface epithelium, edema of the stroma, expressed lymphoplasmocytic infiltration, an increase in the number of lymphoid follicles. [9]

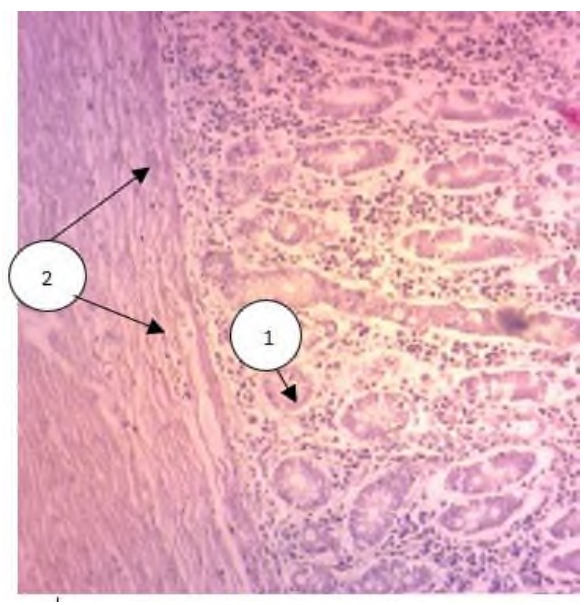

A

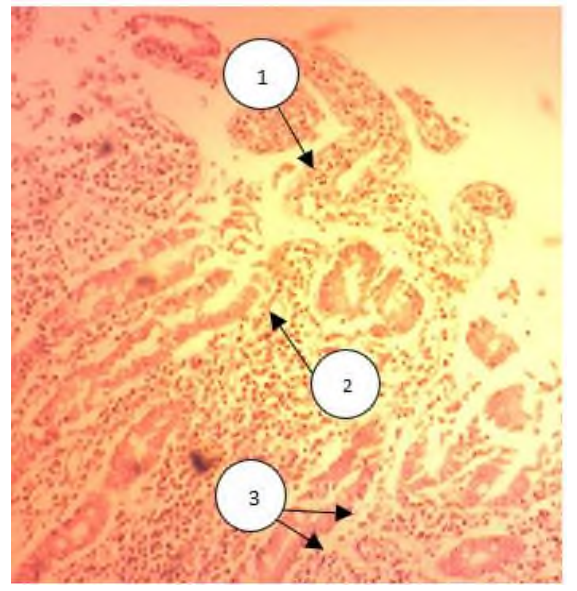

B

Fig. 6. Morphological changes in the 12-digit intestine of pigs as a protein Supplement soy Okara; color with hematoxylin and eosin; UV. 150. A) 1-Brunner's glands without changes, 2-lymphocytic and eosinophilic infiltration, edema of the own plate and loose fibrous connective tissue; B) 1 desquamation of the apical part of the villi; 2 - expansion of the crypt lumen; 3-reduction in the number of goblet cells.

\section{Discussion}

The results of histological studies of the main digestive glands (pancreas and liver), as well as the small intestine allow us to conclude about the negative impact of the abnormal use of soy Okara as a protein Supplement for the fattening group of animals.

In the pancreas, due to an excess of protein and free amino acids in the diet, there was a degenerative degeneration of the endocrine part of the glandular epithelium. In the interstitial tissue, there is an accumulation of fat cells, which also indicates dystrophic changes in the pancreas. The pancreas itself increases in size, which is explained by compensatory processes in the body of fattening pigs. [10,11] 
In the liver, dystrophic changes are also observed due to the toxic effect of excessive amounts of nitrogen-containing compounds on it. The liver, as the main organ involved in protein metabolism, in the processes of deamination of amino acids, is subjected to cirrhotic degeneration with excessive intake of protein and amino acids from feed. Long-term functional load on hepatocytes leads to their partial atrophy and, as a result, a decrease in the function of the organ as a whole.

The small intestine, which is responsible for the active absorption of nutrient hydrolysis products, is also exposed to the toxic effects of ammonia and its compounds. As a result of the negative effect of prolonged feeding with high-protein feeds, the mucous membrane of the small intestine, in particular the 12-digit intestine, is subjected to atrophic diffuse changes with desquomation of surface epithelial cells. The number of villi decreases, which causes a decrease in the absorption surface of the intestinal mucosa, and as a result, the supply of energy and building material to the animal's body decreases. [12,13]

All these changes are not critical for the body as a whole, since the basic physiological constants do not change, that is, the animals remain clinically healthy. However, the technology of intensive fattening provides for the maximum possible absorption of nutrients and an increase in the body weight of the animal. Only under these conditions is the return on feed and maintenance costs achieved. [14]

When using soy Okara for fattening pigs, livestock breeders of the Amur region do not receive the expected gains and incur economic losses.

\section{Conclusion}

Okara obtained from processing soy grown in the Amur region contains twice as much raw and digestible protein as the product produced in the Western regions of our country. [15] Abnormal use of this protein Supplement in farms of the Amur region negatively affects the fattening indicators of pigs.

High content of protein, free amino acids contained in soy Okara, cause destructive changes in exocrine cells of the pancreas, protein-fat dystrophy of the liver, chronic superficial duodenitis. These changes reduce the functions of these organs of the digestive system and as a result reduce the digestibility and digestibility of nutritional components of the feed.

\section{References}

1. V. G. Vertiprakhov, K. V. Borisenko, Digestion and biochemical parameters of blood of chickens when introducing exogenous protease into the diet, Siberian Bulletin of agricultural science 49(2), 77-84 (2019) https://doi.org/10.26898/0370-8799-2019-210.

2. S. V. Dezhatkina, A. Z. mukhitov, A. S. Baryshev Composition and use of soy Okara as a protein additive in animal feeding, Scientific herald, Dimitrovgrad 5, 34-37 (2006)

3. B.Y. Yoshida Alkaline hydrogen peroxide improves physical, chemical, and technofunctional properties of okara, Food Chemistry 323, 1 (2020)

4. S. Dezhatkina, A. Dosorov, N. Lubin The concentration of mineral elements in the blod pigs using supplements of soy okara Nauka I studia 11, 137-146. (2015)

5. V.G. Vertiprakhov, I.A. EgorovThe influence of feed intake and conditioned reflex on exocrine pancreatic function in broiler chicks Open Journal of Animal Sciences 6(4), 298-303 (2016) doi: 10.4236/ojas. 2016.64034 
6. L. I.Drozdova, A. V. Puzyrnikov Morphology of a liver of pigs at the end of sagination at traditional technologies Agrarian Bulletin of the Urals 11, 20-23 (2015)

7. L. I. Drozdova, A.V. Puzyrnikov Morphology of the pig liver at the end of fattening with traditional technologies Agrarian Bulletin of the Urals 11 (141), 20 (2015)

8. G. Wu, F. W. Bazer, G. A. Johnson, Y. Hou Board-invited review: Arginine nutrition and metabolism in growing, gestating, and lactating swine Journal of Animal Science, 96, 12, 3, 5035-5051 (2018)

9. V. I Boyev. Anatomy and histology of farm animals (2015)

10. M. D. Denbow Gastrointestinal anatomy and physiology. In: Sturkie's avian physiology, Elsevier, 337-367 (2015)

11. V. I. Fisinin, V. G. Vertiprakhov, A. A. grozina, L. V. Khasanova Pancreatic secretion and assimilation of amino Acids in the intestines of chickens at different sources of protein in the diet Agricultural bmology 52, 374-381 (2017)

12. S. Lee, D. Zhu, K. Lee Soy tofu Balance Okara: Composition, Recycling, and related limiting factors SRN organization of industrial production. Graduate School of life and environmental Sciences, University of Tsukuba, 1-1-1 Tennodai, Tsukuba, Ibaraki 305-8572. Article ID 423590. P. 8. (2015)

13. S. V. Dezhatkina, N. A. Lubin, A.V. dozorov, M. E. Dezhatkin.Rational use of soy Okara in the diets of young pigs International agricultural journal 5, 40 (2017)

14. I.C. Okoli, C.C. Achonwa, I.P. Ogbuewu Impact of on-farm feeding practices on the reproductive indices of pigs reared under educated smallholder system in Imo State, Nigeria Tropical Animal Health and Production 51, 4, 1 831-837 (2019)

15. I.S.Smirnova, M.E Dezhatkin Razrabotka smesi telyakormov dlya zhivotnykh materialy Mezhdunarodnojauchno-prakticheskoj konferencii molodykh uchenykh «Innovacionnye idei molodykh issledovatelej dlya agropromyshlennogo kompleksa Rossii».159-161 (2016) 